Ankara. For a general reader, the blend of fact and personal narrative is enticing, reminiscent of the mixed fermentations practised by our Neolithic ancestors; but some academics, thirsty for footnotes, may wish he had chosen a more traditional form.

McGovern begins by speculating about the role of alcohol in the Palaeolithic period, suggesting that its shamanic use, alongside other drugs, helped to develop religion and art - a proposition that is impossible to test conclusively. Neolithic and early Bronze Age cultures produced pottery and metal vessels, from which residues can be analysed. In most cases, the first fermentations were mixtures of grains, honey and wild fruit. Grains presented a problem to early brewers because the starch in the grains had to be converted to sugar before fermentation could begin. This was solved in various ways in different cultures: the use of enzymes in human saliva to break down starches is still applied in Africa and the Andes; malting and kilning of the grains is another technique, raising the possibility that beer came before bread; and the use of mould is often found in Asian rice-based brews.

Mixed fermentations, starting with higher sugar concentrations and natural yeast derived from honey and fruits, resulted in beverages of higher alcohol content than those based solely on grains. As cultures gained experience, most moved to single fermentations - beer, fruit wines or mead - with one type of beverage gaining dominance. The social importance of these beverages is reflected in the elaborate nature of fermentation vessels and drinking sets found in tombs in Asia, Europe and the Americas. Alcohol's widespread use is attested in paintings on vessels depicting communal sipping of one drink through shared straws, a scene repeated across many cultures.

The most powerful argument for alcohol as a force for innovation and social development is the claim that the initial domestication of many grains was "motivated by a desire to increase alcoholic-beverage production", rather than to provide more food. However, only one example is explored in the book, namely the suggestion that humans were

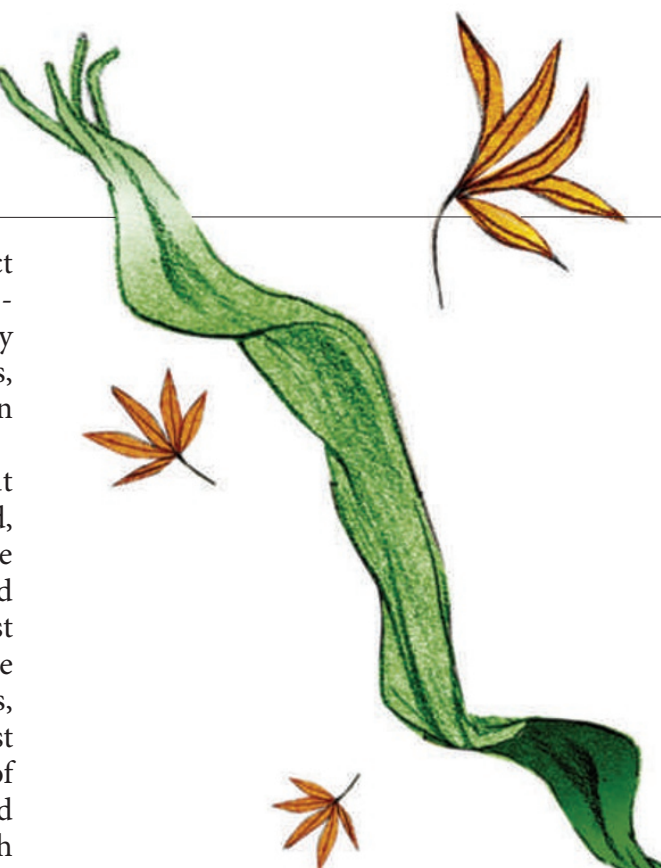

originally attracted to teosinte grass and maize (corn) because of the fermentable sweet syrup in its stalks, and that our selection of the seed kernels of these plants for food followed only afterwards.

The broader case centres on alcohol's perceived ability to spark creativity in some individuals, encouraging them to progress beyond tradition. In the words of William James: "Sobriety diminishes, discriminates, and says no; drunkenness expands, unites and says yes." Although that general argument resonates with this reviewer, McGovern doesn't give any specific examples of social advancement through alcohol consumption.

Uncorking the Past doesn't prove McGovern's thesis that alcohol has been a significant force in human development, but it does demonstrate that fermented beverages have been incorporated into the fabric of society for millennia. For some, taking a 'cup of kindness' may be a ticket to altered consciousness; for most, it invites sociability through temporary effects to our

limbic system. Both outcomes are sorely needed in today's society.

Jim Lapsley is adjunct associate professor in the Department of Viticulture and

Enology at the University of California, Davis, 1 Shields Avenue, Davis, California 95616-5270, USA.

e-mail: jtlapsley@ucdavis.edu

\title{
Living by the calendar
}

\section{The Seasons of Life: The Biological Rhythms that Living Things Need to Thrive and Survive \\ by Russell Foster and Leon Kreitzman \\ Profile Books/Yale University Press: 2009 320 pp. $€ 20 / \$ 28$}

Much of biology is governed by the seasons. Reindeer seasonally adjust the colour of their eyes for better vision; newborn warblers are programmed to fly from Europe to an unknown destiny in Africa; hibernators turn down their internal thermostat for six months of the year. Most biologists would jump to unravel such seasonal feats if the time constraints were not so forbidding. Russell Foster and Leon Kreitzman lament in their latest book the slow pace of research on annual rhythms in biology. Yet their fascinating story impresses with its wealth of facts and splendid overview.

The Seasons of Life follows on from the authors' previous collaboration, The Rhythms of Life (Profile Books, 2004). Russell Foster, a professor in circadian neuroscience at the University of Oxford, UK, is an eminent scientist in the field of chronobiology, and a passionate one. He helped to discover specific ganglion cells in the mammalian retina that perceive light intensity and are instrumental in synchronizing biological clocks. Kreitzman is a science journalist with a lucid pen. Together, they paint a broad perspective on the functions and mechanisms of biological calendars.

The authors dedicate five chapters to the adaptation of animals and plants to the

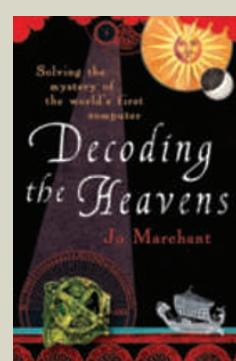

Decoding the Heavens: Solving the Mystery of the World's First Computer

by Jo Marchant (Windmill Books, $€ 8.99$ )

The 2,000-year-old Antikythera Mechanism was found in 1901, but its significance was only recently revealed. "[This] gripping and varied account will propel the mechanism to greater fame, although it may never achieve the celebrity of the Rosetta Stone that it probably deserves," argued Andrew Robinson in his review of the hardback edition (Nature 455, 867-868; 2008).

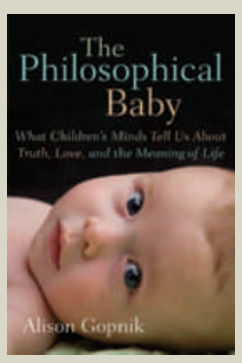

The Philosophical Baby: What Children's Minds Tell Us About Truth, Love, and the Meaning of Life

by Alison Gopnik (Bodley Head, E14.99) Alison Gopnik's well-written book is an unusual look at the conscious mind. Drawing on research and her own pioneering studies, she reveals that processes in a baby's mind can be as complicated as those in the minds of adults, and asks what brain development can teach us about humanity. 
seasons, and six to human seasonality. This preference for humans is unexpected, but appropriate and stimulating. Research interest in human seasonality has been considerable but necessarily of a descriptive nature. The annual rhythm of human reproduction, for example, is well known and has been recorded extensively in birth records. Evolutionary zoologists can only dream of having similar vast data sets.

Until recently, the consequences of birth date for human characteristics was a theme for astrologers rather than scientists. Database analyses now show that the incidence of a host of diseases later in life, such as schizophrenia, multiple sclerosis and suicidal behaviour, varies with the season of birth. This seasonal variation, the authors argue, holds the key to understanding the impact of environmental effects during gestation and early postnatal

\section{This
argue,}

(1)
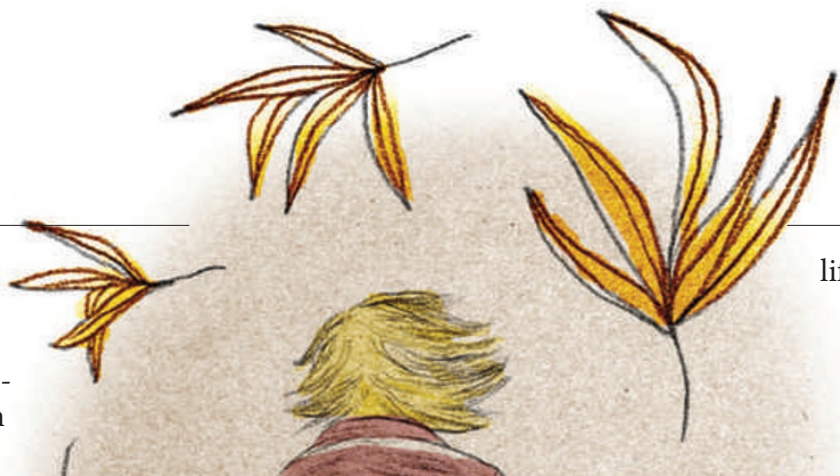

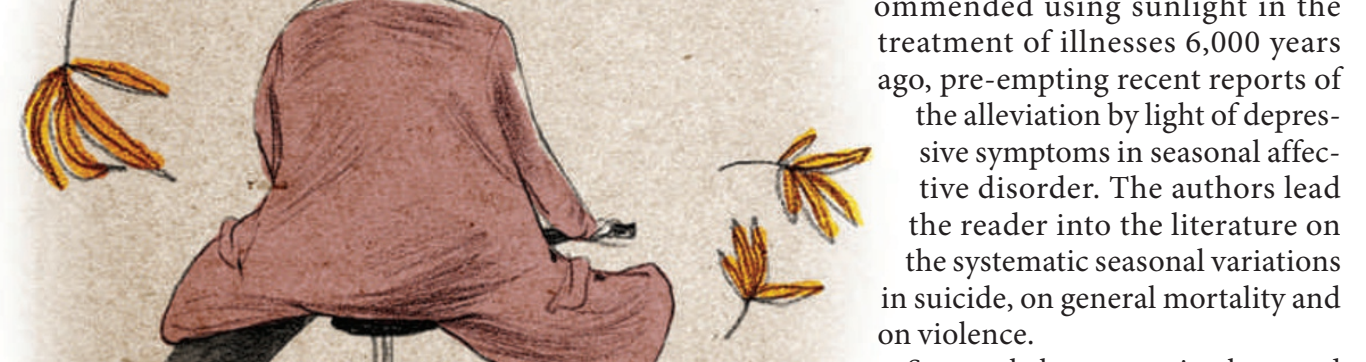

Seasonal phenomena in plants and animals are more readily approached by experimentation than are those in humans. The book tells the story of the discovery of photoperiodism - the study of the physiological changes in reaction to the length of daylight - first by Wightman Garner and Henry Allard in plants in 1920, and then by William Rowan in songbirds in 1925. The authors also detail the 
finding of innate circannual clocks: endogenous seasonal rhythms that persist even in constant temperature and day length with a usual cycle length of around 300 days rather than 365 days. Circannual clocks were first found in hibernating ground squirrels by Eric Pengelley in 1966, and in seasonally migrating songbirds in 1967 by Ebo Gwinner, the influential ornithologist to whom the book is dedicated. In the 40 years since then, significant progress has been made by only a few labs. The physiology of the

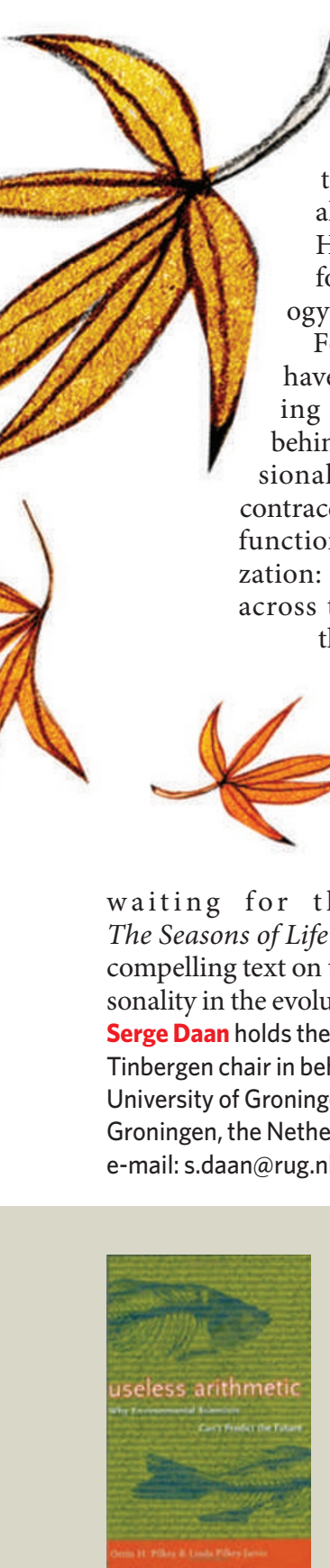

circannual pacemaker in the Soay sheep, for example, is becoming better understood through studies by Gerald Lincoln and David Hazlerigg at the Centre for Reproductive Biology in Edinburgh, UK.

Foster and Kreitzman have produced a tantalizing account of the facts behind seasonality. Its occasional nickname, 'nature's contraceptive', reflects the key function of seasonal organization: thousands of species across the globe, including those in the tropics, use seasonality to turn off reproduction at times of year when low food supply is expected and individual fitness is better served by waiting for the next season. The Seasons of Life is a joy to read, and a compelling text on the importance of seasonality in the evolution of life on Earth. Serge Daan holds the honorary Niko

Tinbergen chair in behavioural biology at the University of Groningen, PO Box 72, 9700 AB Groningen, the Netherlands. e-mail: s.daan@rug.nl

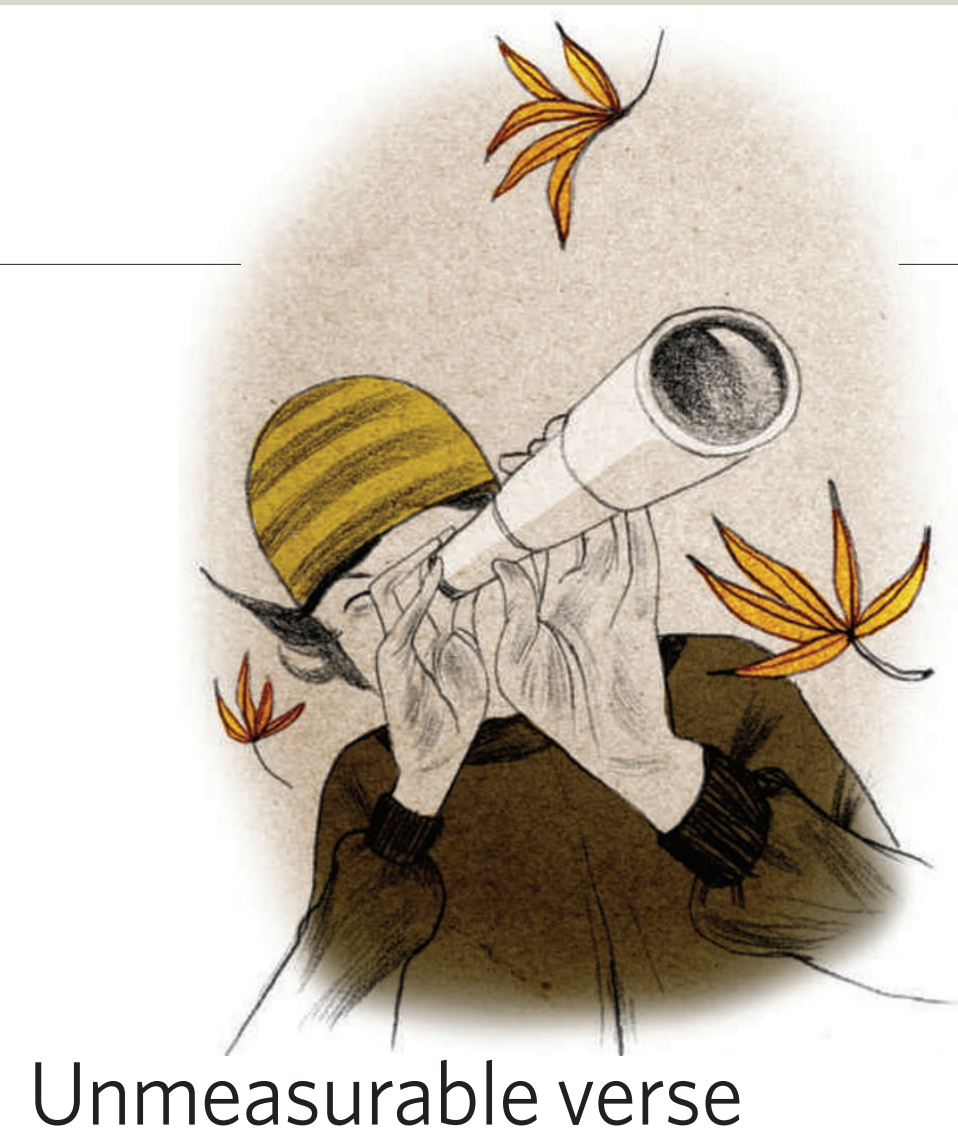

Physicist and author Alan Lightman's latest work is a book-length poem. In Song of Two Worlds, he writes from the perspective of a man reassessing his life after a tragedy. Lightman splits his epic into two sections; in the first, he marvels at the measurable world, the glory of geometry and fact. In the second, he explores the unmeasurable, the pleasure and pain of love, the beauty of a sunset and the night sky. An excerpt from the latter section is reproduced here.

\section{Excerpt from Song of Two Worlds}

I am a fragment

That hurtles through space

While the breeze of the universe

Ruffles my hair.

Evening. I gaze

Through my telescope,

Searching the colors of stars.

Some are the hues of goats' wool,

Some ochre olive,

Or pink bougainvillea.
In chasms of space

I see stars born from gases,

Great thrumming furnaces oozing their heat,

Convective motions, electron opacities -

Elsewhere stars dying,

Cold cinders

Or giant explosions, eruptions of light,

Cities consumed in a nuclear blast,

Billions of years dimmed in a second.

\begin{abstract}
I have learned
That the heavens are violent and fragile

And doomed to destruction,

Just as this thimble the earth.

All in the cosmos is failing,

And nothing remains,

And we measure the hour of the stars,

As I measure one morning's light.
\end{abstract}

Here, in the glass of this eyepiece.

Song of Two Worlds

by Alan Lightman

A. K. Peters: 2009.112 pp. $\$ 24.95$
Useless Arithmetic: Why Environmental Scientists Can't Predict the Future by Orrin H. Pilkey and Linda Pilkey-Jarvis (Columbia Univ. Press, E15.50)

Reviewer Roger Pielke Jr wrote: "The authors have identified a critical challenge confronting the modern scientific enterprise: our ability to produce model-based predictions seems to have outpaced our ability to use such tools wisely in decision-making." (Nature 447, 35-37; 2007.)
Oliver Morton

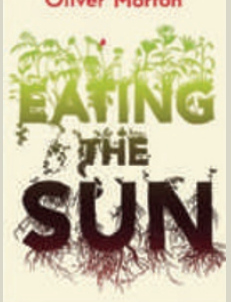

\section{Eating The Sun}

by Oliver Morton (Fourth Estate, £9.99)

There are few books on photosynthesis for the nonspecialist. Eating the Sun fills that gap, covering the history of its discovery and its processes. "Morton's account of the ubiquitous importance of photosynthesis is an original viewpoint for looking at the world. It is written with verve and an eye for detail. His breadth of scholarship could leave other science writers green - with envy," wrote reviewer Richard Fortey (Nature 449, 284-285; 2007). 